\title{
A ESPACIALIDADE NA COMPREENSÃO DO TRANSTORNO DO PÂNICO: UMA ANÁLISE EXISTENCIAL
}

\author{
The spaciality in the understanding of the panic disorder: an existential analysis \\ La Espacialidad en la compreensión del transtorno de panico: una análisis existencial
}

Gustavo Alvarenga Oliveira Santos

\begin{abstract}
Resumo: O texto apresenta um caso clínico sob a luz da análise existencial de Ludwig Binswanger. Elege-se a espacialidade como categoria central na compreensão clínica aqui apresentada. Em um primeiro momento, será apresentado ao leitor o conceito de espacialidade segundo a ontologia fundamental de Heidegger, em Ser e Tempo. Feito isso, o artigo traz à luz o conceito de pânico, de acordo com a análise existencial. O relato do caso clínico, bem como sua análise, conforme os conceitos apresentados, desvelará de que forma o pânico pode ser entendido como um transtorno no modo de espacializar. Essa compreensão nos dará subsídios para um entendimento existencial do transtorno do pânico, bem como nos possibilita pensar em formas de condução do tratamento, diferente das tradicionais.
\end{abstract}

Palavras-chave: Transtorno do pânico; Análise existencial; Espacialidade; Binswanger.

Abstract: This text presents a clinical case under the light of the existential analysis of Ludwig Binswanger. It is chosen spaciality as central category in the clinical understanding presented here. At a first moment, basic on the essential ontology of Heidegger in Being and Time, will be presented to the reader the concept of spaciality. Made this, the article brings to the light the concept of panic, in accordance with the existential analysis. The story of the clinical case, as well as its analysis, will reveal of that it forms the panic can be understood as a disorder in the way of to space of the individual. This understanding in will give us subsidies for an existential agreement of the panic disorder, as well as in makes possible to think about forms of conduction of the treatment, differently of the traditional ones.

Keywords: Panic disorder; Existential analysis; Spaciality; Binswanger.

Resumen: Este trabajo presenta un estudio de caso a la luz del análises existencial de Ludwig Binswanger. Elige a la espacialidad como uma categoria central en la comprensión del caso. En un primer momento, el lector se introducirá el concepto de espacialidad de acuerdo a la ontología fundamental de Heidegger, en Ser y Tiempo. A continuación, el artículo saca a la luz el concepto de pánico, de acuerdo con el análisis existencial. El caso clínico y su análisis dará a conocer como el pánico se puede compreender como un transtorno en el modo de espacializar. Esa comprensión subsidiará para un entendimento existencial del transtorno de pânico, mientras possibilitará piensar en modos de conducción del trataimiento, diferente de los tradicionales. Palabras-clave: Transtorno de pánico; Analísis existencial; Espacialidad; Binswanger.

\section{Introdução}

Este texto se propõe a discutir um tema recorrente na clínica psicológica e psiquiátrica: o transtorno do pânico. Para tanto, utilizaremos a categoria da espacialidade, tal como entendida pela Antropologia Fenomenológica de Ludwig Binswanger, na análise de um caso clínico. Em um primeiro momento, será esclarecido o significado do termo alemão Da-sein, em acordo com a ontologia fundamental de Martin Heidegger, presente em Ser e Tempo. Esse conceito é base, e é a partir dele que entenderemos a categoria da espacialidade conforme a Analítica do Dasein.

O médico suíço Ludwig Binswanger foi um dos psiquiatras inspirados pela nova perspectiva em que o ser do homem era concebido por Heidegger. A compreensão do homem como Dasein permitia possibilidades de compreensão das patologias mentais, embasados nos modos de relação homem-mundo. Destacaremos nesse texto aspectos do ser do homem como Dasein, no sentido de elucidar um caso clínico, em especial no que tange à questão da espacialidade, já abordada por Heidegger e aplicada por Binswanger em sua psicopatologia.

Binswanger elucida essa relação da compreensão do homem como Dasein nos casos clínicos reunidos no livro Schizophrenie, publicado em 1957 (e inédito em português), onde aparecem os casos: Ellen West (1944-1945), Use (1945), Jürg Zund (1946-1947), Lola Voss (1949) e Suzan Urban (1952-1953). Nessa mesma época é também publicada a obra: Três Formas de Existência Malograda: Extravagância, Excentricidade, Amaneiramento (Binswanger, 1956/1972) ${ }^{1}$ em que são evidenciadas a partir da compreensão do Dasein, al-

\footnotetext{
Título original: Drei Formen missglückten Daseins. Verstiegenheit, Verschrobenheit, Manieriertheit.
} 
guns modos de ser que aparecem na esquizofrenia. Após essa fase, segundo Giovanetti (1990), o autor se utilizará da fenomenología transcendental de Edmund Husserl na análise de algumas patologias. Essa nova fase do pensamento de Binswanger se expressa, por exemplo, em Melancolia e Mania. Estudos Fenomenológicos ${ }^{2}$ (Binswanger, 1960/1987), publicado em 1960, aparecerá nas considerações finais quando justificaremos por que o caso relatado não se trata de uma psicose.

Descreveremos brevemente o caso "Suzanne Urban", último estudo clínico do autor, em uma perspectiva Daseinsanalítica, onde nos interessa a noção do Terror, que na aproximação de Pereira (1997), serve-nos para a compreensão do hoje chamado Transtorno do Pânico. Alguns apontamentos teóricos, relevantes da análise existencial, empreendida por Binswanger nesse caso, servirão como subsídio para a discussão de um caso clínico de transtorno do pânico atendido pelo autor deste texto.

A descrição desse caso e sua análise, sob um ponto de vista analítico-existencial, alicerçado à categoria da espacialidade, contribui para um entendimento desse transtorno, tanto do ponto de vista teórico, como do ponto de vista da condução do tratamento.

\section{O Modo de Ser-em Espaço: A Espacialidade do Da-sein como Dis-tanciamento}

Devemos esclarecer de antemão a que nos referimos quando nos utilizamos do termo Da-sein. Traduzido comumente por pre-sença, graças à edição atual de Ser e Tempo em português, o conceito tem gerado uma série de equívocos e mal entendidos quando utilizado à revelia da genuinidade que ele traz na concepção de homem atual. Preferimos neste texto, assim como tem sido utilizado por estudiosos da analítica existencial, utilizar o termo em alemão: Da-sein, para preservarmos o seu sentido original e nos livrarmos das ambiguidades presentes na tradução latina, alvo de muitas discussões entre os especialistas da área.

Longe de querermos alongar muito no tema e nos debatermos em questões filosóficas de ordem ontológica, cabe-nos, para o que nos interessa neste artigo, demonstrar o pano de fundo sobre o qual foi concebido o conceito, de forma que se torne claro a espacialidade implícita na sua própria concepção.

Da-sein foi o termo utilizado por Heidegger em Ser e Tempo, na busca de um ente em que poderia se colocar a questão sobre o Ser ${ }^{3}$. O Ser, segundo o autor, havia caído no esquecimento em um mundo cada vez mais dominado pelo tecnicismo científico que o transformou em

\footnotetext{
2 Título original: Melancholie und Manie. Phänomenologische Studien (inédito em português).

3 Para distinguirmos o Ser (Sein) em geral e o ser em particular, utilizaremos o primeiro com maiúscula e o segundo com minúscula. O Ser em geral é ontológico, pois se refere à questão sobre aquilo que é, já o ser do Da-sein é particular, pois se singulariza no ente $D a$-sein.
}

um ente. A palavra $D a$ - é pronome demonstrativo, significa "Aî"; sein, "ser"; logo Ser-aí, é sua tradução literal. Da-sein é o ente através do qual o Ser é em relação, tornando assim possível a pergunta sobre ele mesmo. Da-sein é o homem enquanto existente, ou seja, imbuído da tarefa primordial de ter que constituir seu próprio ser, e nesse processo ser o ente através do qual é possível uma pergunta sobre o Ser em geral.

Interessa-nos, para este trabalho, apreendermos no Da-sein seu caráter eminentemente espacial. Destaca-se, que o modo pelo qual esse aparece, pressupõe de antemão uma relação intrinsecamente espacial já denotada em sua nomeação. O "Aî” é uma relação direta com o espaço: sendo em relação, o homem não é aqui, junto com as coisas, mas tem que existir orientado para elas.

Enquanto um existente, que se orienta para algo, o homem tem entre si e o mundo um distanciamento, segundo Heidegger (1927/1997, p. 157): “(..) o que se acha à mão no mundo circundante, pode vir ao encontro em sua espacialidade”. Desse modo o Da-sein estabelece o seu ser-no-mundo, espacializando, e seu espacializar desvela que a relação com as coisas não é dada de antemão, mas se dá enquanto ultrapassa o distanciamento inerente à sua condição.

O modo como um indivíduo particular espacializa, é, para Binswanger, uma categoria importante na compreensão das patologias mentais. $\mathrm{O}$ autor destaca no entendimento nos casos clínicos "Lola Voss" e "Suzanne Urban" essa categoria como elemento central para o entendimento das consequências da experiência que ele denomina como Terror.

O Terror se dá na vivência direta do abismo, no distanciamento que há entre o $\mathrm{Si}$ e as coisas. A existência ${ }^{4}$ é uma condição abissal, pois no seu espacializar, ela se faz sobre o nada. Ela não é fundamentada, não é com o mundo, mas no mundo, ou seja, em relação a ele. O Terror é uma forma de Angústia, e essa última é o sentimento privilegiado que revela ao Da-sein seu modo de ser sobre o nada. No domínio da inautenticidade, o Da-sein se crê fundamentado no próprio solo que ele criou para habitar, alienando-se. Quando esse solo se revela inautêntico através da vivência da angústia, o existente se vê sob o domínio de "ter-que-ser-si-mesmo" - que é a expressão utilizada por Binswanger na análise do caso Suzanne Urban, e que se refere à dimensão própria do existir que se caracteriza em ser irremediavelmente responsável por seu próprio ser-no-mundo - e o solo aparece como abissal. Chamond (2011) ao propor um estudo sobre a psicopatologia do espaço vivido de acordo com Binswanger destaca que para o autor:

A imagem da queda expressa uma possibilidade concreta da espacialidade vivida, do corpo habitando o espaço: ela é uma estrutura antropológica do mundo,

\footnotetext{
4 Ex-sistere significa ebulência, emergência, salto além de si. Segundo Heidegger é a tradução latina mais próxima ao conceito de Da-sein.
} 
uma forma de habitá-lo, aquela da perda do apoio e da harmonia, da ruptura em uma corporeidade tranqüila. Mas além do corpo que cai realmente, a imagem da queda traduz a essência mesma da perda do escoramento e do vivido de terror que lhe é consubstancial. A queda descreve uma possibilidade fundamental de ser no mundo: a perda do equilíbrio, o colapso, o terror (p. 5).

O “ter-que-ser-si-mesmo", dá-se, no entendimento heideggeriano, como projeto (Entwurf). Entendendo o ser como projeto em acordo com a categoria da espacialidade, podemos dizer que o primeiro é como um elo que nos conecta às coisas que nos circundam. Quando esses elos que construímos com o mundo perdem seu fundamento, o nada sobre o qual eles foram construídos torna-se evidente, e a angústia torna-se o sentimento prevalente. Ou seja, se os projetos de determinado sujeito quedam ameaçados, é a existência mesma que perde seu fundamento, como se já não tivesse laços que a una às coisas do mundo; em termos binswangerianos, essa existência torna-se malograda.

Boss (1977) relata o caso de um paciente esquizofrênico que percebia da janela um mundo próximo, bidimensional e ameaçador que o comprimia. Esse paciente também apresentava os chamados sintomas negativos da esquizofrenia: embotamento afetivo, lentificação do pensamento e autismo. Ou seja, o modo como se comprimia e se limitava na forma de Ser aí, também era o modo como espacializava, trazendo para a proximidade os entes enquanto algo que o comprimia. Da mesma forma, um outro paciente pode perceber o espaço como profundo e desafiador, luminoso e amplificado, nesse estado ele aparece como que tomado por uma sensação de êxtase, como se o mundo fosse dotado de infinitas possibilidades de existência.

Cabe-nos nesse artigo demonstrar em um caso clínico específico a forma como se dá a espacialização no chamamos, atualmente, de "Transtorno do Pânico". Antes disso, porém, veremos como Binswanger (1957/1988) evidencia o pânico no caso “Suzanne Urban”. Esse se revelará para ela como experiência do Terror, que a paciente vivenciará como evidência não mediada do abismo, o que ameaça sua existência como um todo.

\section{O Caso Suzanne Urban: Terror e Pânico como Perturbação da Dimensão Espacial}

Sobre a experiência da angústia do abismo, Binswanger (1957/1988) propõe a noção de Terror. O Terror é a constatação do Da-sein de sua facticidade ${ }^{5}$. Enquanto

\footnotetext{
5 A facticidade (Geworfenheit) refere-se à condição do Da-sein enquanto ser lançado no mundo, "num abandono no meio do ente que o põe frente à única possibilidade de constituir-se ele mesmo o seu ser" (Pereira, 1997, p. 37).
}

vivência, ele vem como algo que lhe toma de fora e que aparece como que estando o Da-sein presa de uma potência superior.

O abismo traz-lhe a possibilidade sempre presente de não ser ele mesmo e, paradoxalmente, o mantém à vista as múltiplas possibilidades de ser como projeto. Essa experiência, segundo Binswanger (1957/1988), é típica da psicose em que o próprio modo de constituição do ser-aí se perde na noção mesma de se orientar no espaço.

Binswanger (1956/1972) estabelece três formas de "existência malograda" como modos de ser típicos da esquizofrenia, são elas: o maneirismo, a excentricidade e a extravagância. Na extravagância, o abismo é encarado pelo Da-sein como algo a ser transposto, o salto que se dá para o seu atravessamento, porém, queda desproporcional com a possibilidade mesma do projeto, ficando o indivíduo preso em sua própria forma de espacialização. Sem referências para as quais se orientar, o extravagante torna-se como um alpinista que, ao escalar uma montanha, perde a noção de fundo que lhe abriria a possibilidade do próximo passo ou do possível retorno. O terror é vivenciado diretamente, pois ele paira sobre o abismo e o nada lhe aparece evidente.

Já no caso Suzanne Urban, a experiência do abismo se dá de outro modo e o aterrorizante vem como algo de fora. Suzanne é descrita por Binswanger (1957/1988) como uma mulher extremamente cuidadosa com relação aos seus cuidados pessoais e os dos outros, principalmente nos aspectos ligados à saúde dos seus entes queridos. O seu processo psicopatológico começa quando acompanha seu marido em uma consulta rotineira a um urologista para tratar de um possível problema urinário. Qual não foi a surpresa quando o médico diagnostica nele um câncer de vesícula praticamente inoperável.

A cena do médico proferindo o diagnóstico retém-se na memória de Suzanne. Ela passa a se ocupar do tema, o que repercute no sentido de sua orientação espacial, onde irá prevalecer o mundo enquanto perigo. A cena do diagnóstico de câncer é deslocada para todas as suas formas de relação com o mundo e, em seu modo de espacialização, passa a predominar o que Binswanger (1957/1988) chama de "atmosferização do tema”. Assim a ameaça não se refere ao medo pela morte do marido, como poderia se supor, mas toma toda a forma de mundo no espaço que a paciente habita. Temos aqui então a "atmosfera do terror".

Na "atmosfera do terror", o modo como Suzanne espacializa não se ancora mais nas relações possíveis que lhe são dadas; pelo contrário, ela cerceia seus modos de relação e as coisas trazem a sempre iminente possibilidade de seu aniquilamento. Daqui podemos deduzir o pânico, como modo de experiência de um terror atmosférico que ameaça o ser de fora, sem se mostrar em nenhum ente específico, mas no espaço como um todo. Daí que as crises de pânico quando muito recorrentes podem desenvolver o que em psiquiatria chama-se agorafobia, ou 
seja, em um pavor inespecífico a espaços amplos e vagos, como apontado por Pereira (1997).

No caso Suzanne Urban, ao lidar com a experiência do Terror, ela passa a criar o que denomina "teatro do horror": imagina forças demoníacas que lhe estão à espreita, fantasia perigos imaginários e sente-se constantemente ameaçada pelos outros. Ou seja, do pânico geral que ameaça seu ser como um todo e é inespecífico, passa a eleger os objetos do perigo, de onde Binswanger (1957/1988) conclui ser a base de evolução de seu delírio.

Na experiência do Terror de Suzanne, não há possibilidade que se elabore qualquer discurso ou entendimento verbal sobre o que a atormenta. Ao criar o “Teatro do Horror”, ela já se familiariza com seus perseguidores, e na personificação do Terror fabula um mundo fantástico onde o perigo se personifica nas pessoas ao seu redor.

Pereira (1997) considera o relato do caso Suzanne Urban como uma possibilidade de entendimento para a experiência do pânico; com a diferença de que no Transtorno do Pânico, o Dasein elege o corpo como lugar de anteparo ao terrífico da experiência do abismo. Segundo Pereira (1997, p. 239): “(...) no pânico, o terrível ancora-se de forma hipocondríaca no real do corpo. Dessa forma, o pânico não pode ser considerado como um inominável inteiramente experimentado como tal". O corpo, assim como no "Teatro do Horror" de Suzanne Urban, serve frente ao abismo do inominável e do nada. Enquanto ainda se é possível uma querela sobre um modo de relação real, o indivíduo se mantém em algum chão, mesmo que à beira do precipício.

Os sintomas do transtorno do pânico aparecem, em geral, como um pavor inespecífico, acompanhados ou não de uma sensação iminente de morte. O pavor, como dito, manifesta-se no corpo por alguns sintomas, segundo o DSM-IV (American Psychiatric Association, 1995): "1 - palpitações ou ritmo cardíaco acelerado; 2 - sudorese; 3 - tremores ou abalos; 4 - sensações de falta de ar ou sufocamento; 5 - desconforto torácico; 6 - náusea ou desconforto abdominal" (p. 193). Os ataques se dão, em geral, quando o indivíduo encontra-se só ou em aglomerações, como congestionamentos e lugares públicos. A ocorrência de um ou dois ataques esparsos não significa, no entanto, que a pessoa desenvolveu o chamado transtorno do pânico. Para que esse se caracterize enquanto tal é necessário, segundo o DSM-IV, que o indivíduo apresente uma preocupação acerca das consequências dos ataques de pânico: ideias de morte, medo de perder o controle, ficar louco ou morrer por parada cardíaca são comuns.

O transtorno surge como uma tentativa do indivíduo defender-se contra o abismo do nada, no corpo ou nas ideações que podem vir a se tornar delírio, como no caso Suzanne Urban. Assim compreendemos o motivo por que as ideações de morte, o medo de perder o controle e ficar louco são comuns; o transtorno desvela um modo de espacializar que se rompeu, deixando vaga a distância que separa o ser de seu mundo, daí as idéias de aniquilamento, ou seja, da perda de sua dimensão existencial.

Vejamos como isso se deu em um caso clínico.

\section{Das Crises de Pânico às Passarelas da Vida: o Caso Lucas}

O atendimento que será relatado ocorreu em um Serviço de Psicologia vinculado a uma Faculdade de Psicologia. O contrato de atendimento, estipulado em um termo de consentimento assinado pelo paciente e seu responsável legal, previa que, por se tratar de um serviço de psicologia universitário, os casos ali atendidos poderiam ser utilizados para pesquisas, bem como material didático para o ensino de psicologia, garantindo o sigilo das informações (em caso de relato), por meio de omissão de elementos que identifiquem o paciente e uso de nomes fictícios. $\mathrm{O}$ autor do artigo atendeu o caso, na qualidade de docente e pesquisador da referida faculdade, interessado por questões relativas aos transtornos de ansiedade.

Chega-me para atendimento clínico um adolescente de 14 anos, encaminhado pela mãe e indicado por um cardiologista. A queixa principal, relatada pela responsável, era que Lucas (nome fictício) estava sofrendo, nos últimos meses, recorrentes crises de arritmia cardíaca, que, segundo o médico da família eram de fundo psicológico, não tendo sido encontrado nenhum problema orgânico que as justificasse.

A mãe foi recebida em particular antes de Lucas ser convidado a ser atendido individualmente. Foi perguntado se ele consentia em participar de um processo psicoterápico. Ele consentiu, mas disse que necessitava do atendimento não pelo motivo exposto pela mãe, qual seja, a arritmia cardíaca. Desse sintoma, ele daria conta, já não o sentia tanto quanto antes, mas o verdadeiro motivo seria conseguir se concentrar melhor nos estudos, dada a necessidade em ser aprovado em um concurso para estudar em uma importante escola técnica federal.

Assim começaram as entrevistas, e Lucas, a princípio, mostrava-se em uma postura distante, desconfiado, ora gaguejando, ora falando muito baixo. Indagava sempre por onde começar e, sentindo no terapeuta, alguém disposto a escutar o que tinha a dizer, foi aos poucos discorrendo sobre suas preocupações cotidianas, bastante típicas para um garoto de sua idade. Vídeo games, computadores, patins, bicicleta, o futebol que praticava, eram temas recorrentes nas entrevistas iniciais. Aos poucos fui me aproximando dele, de seu linguajar próprio, de seus interesses, mostrei-me como parceiro e como quem comungava, na sua idade, dos mesmos interesses.

Lucas era o filho mais velho, tinha mais um irmão de 13 anos, de uma pequena família de classe média. Seu 
pai havia-se aposentado do serviço público, ficando boa parte do seu tempo livre, em casa, a mãe tinha o ensino médio e era dona de casa. Do pai se referia como um homem a quem devia muito sua formação e boa educação. Afinal, estudava em um bom colégio e tinha privilégios como aulas de informática e futebol. Devia também a ele sua possível aprovação no concurso da escola técnica, coisa pela qual era sempre cobrado. O pai dizia que já na idade de Lucas, ele trabalhava e nem podia se dar ao luxo de só estudar, assim ser aprovado no concurso era nada mais que uma obrigação para o filho.

O discurso do pai dominava as sessões. Lucas falava comumente sobre suas queixas: dizia que o pai o chamava de "vagabundo", que ele não daria em nada na vida, que nenhuma mulher o desejaria. Lucas demonstrava certa ambiguidade em relação a isso. Ora considerava essas cobranças pertinentes, o que o inferiorizava diante do pai; ora já se enfastiava de tantas obrigações por ele exigidas, queixando a mim sobre a falta de tempo suficiente para o seu lazer e para ficar à toa como gostaria. Lucas via a mãe como quem apaziguava as cobranças paternas em relação a ele, tentando desviar sua atenção do fato dos adolescentes da casa não estarem atendendo às suas expectativas. $\mathrm{O}$ paciente, no entanto, insistia em ter seus momentos de lazer, o que irritava ainda mais o pai, tornando suas reclamações recorrentes.

Com o quadro de sua situação já apresentado e os relatos se voltando a esses temas, ora ao lazer e aos jogos de futebol, ora aos estudos e a cobrança excessiva do pai, Lucas começou a dizer sobre sua preocupação com a morte. Quando indagado se já tivera alguma perda significativa em sua vida, de pronto se lembrou da morte repentina de seu avô, com quem tinha um vínculo muito significativo.

Lucas descreve o avô em contraposição ao pai, como sendo mais relaxado e menos exigente, e que desbancava, sempre que tinha oportunidade, a postura parcial e autoritária do seu genitor. $\mathrm{O}$ avô, segundo ele, dizia que seu pai não era nada disso que ele tentava se mostrar e que havia tido condições para estudar, fazer seu curso superior e depois poder exercê-lo como funcionário público, sendo que suas exigências não faziam sentido, não era um exemplo sobre aquilo que ele próprio dizia. O avô também era alguém com quem se podia jogar sinuca, totó, xadrez; pessoa festiva e tranqüila, Lucas se assustou com sua morte. Ao falar desse fato, ocorrido há aproximados três anos, ele fez questão de salientar que não tinha relação com seus sintomas; aliás, os sintomas há muito não lhe incomodavam, mas foram reaparecendo logo após a sessão em que se falou sobre essa morte.

Os "sintomas", como o próprio Lucas a eles se referia, apareciam como pontadas no peito que sentia quando jogava bola, dormia ou devido a esforço físico razoável; sentia uma palpitação diferente no coração. Em algumas situações, chegou a pedir à família que contatasse o Serviço de Atendimento Municipal de Urgência (SAMU) que lhe atendeu em pelo menos três ocasiões, em que sendo levado para o serviço de cardiologia do pronto-socorro, nada se constatou de anormal.

Fora os "sintomas", eram recorrentes as ideias de morte e de ameaça constante. O prédio onde estudava, por exemplo, podia desabar a qualquer momento. Segundo seu relato a engenharia ainda não atingira seu grau de perfeição, assim todas as construções guardavam uma ameaça latente de desabamento. As escadas também guardavam a morte em potencial, um deslize, um degrau a menos ou a mais no cambiar das pernas, poderia lhe provocar uma queda súbita. A morte de um humorista famoso na televisão, repentina por um ataque cardíaco, foi um dos desencadeadores de um ataque: ora se era assim, como acontece a qualquer um, isso poderia ocorrer com ele também. Sabia da irracionalidade de seus medos, confiava em parte no diagnóstico dos médicos, mas não conseguia se livrar, segundo ele, dessa sensação iminente de morrer que lhe rondava.

Aos poucos foi se recolhendo mais em casa, e, embora as pressões do pai lhe incomodassem, sabia que ali, pelo menos, era um lugar razoavelmente seguro, sentindo-se um tanto livre das ameaças constantes da rua. Nesse tempo largou o futebol e reduziu ao máximo suas atividades, inclusive faltou a várias sessões de psicoterapia. Ia à escola sempre acompanhado do irmão e sentia sempre as palpitações ao atravessar a rua, ou subir as escadas.

As queixas do pai se atenuaram e os recorrentes ataques passaram a ser tematizados em nossos encontros. Nesse tempo Lucas já estava há seis meses em psicoterapia, interrompidos por vinte dias de férias, quando outras crises mais severas haviam lhe acometido.

Retornado das férias apressou-se em dar seu diagnóstico: síndrome do pânico. E pedia incessantemente um encaminhamento a um psiquiatra ou que lhe propusesse uma técnica que o livrasse logo daquilo. Respondi que na nossa proposta deveríamos nos atentar ao significado que "os sintomas" tinham para ele, e não em simplesmente expulsá-lo da sua vida; que era algo que deveríamos descobrir juntos e que, com certeza fazia parte da totalidade de sua existência. Confiou. As sessões pareceram mais produtivas, principalmente em verbalizações e as crises foram-se reduzindo até o momento em que ele tratou do tema das passarelas. As passarelas segundo ele, traziam um desafio ainda maior, pois se tratavam de construções, vulneráveis como quaisquer outras, mas que pairam nos abismos, rios e avenidas movimentadas da cidade.

Citou os diversos tipos de passarelas existentes, das estreitas às mais largas, das precárias de estrutura metálica construídas às pressas sob interesses políticos, às antigas de cimento, já velhas e com pouca ou nenhuma inspeção de engenheiros. Sempre se debatera com elas, lembrou. Isso desde sua infância, seu pai uma vez o forçou a atravessar uma, puxando-o violentamente pelas mãos até ele ser arrastado, chorando e se debatendo, pavoroso. Na medida em que os sintomas se acalmavam e 
ele se interessava cada vez mais pelas construções arquitetônicas, contou-me sobre um feito recente.

Uma passarela suspeita, estreita, dessas antigas, havia o desafiado a uma travessia. Ele precisava atravessá-la para verificar um possível estágio numa empresa especializada em recrutamento. $\mathrm{O}$ desafio o emocionou, a ponto de chorar; sentia, paradoxalmente, uma ânsia em chegar e certa vontade de ficar, enfim resolveu que iria enfrentar seu medo e atravessar a passarela. Essa era estreita, e para ele, das mais temíveis, pois se angustiava mais com as estreitas e menos com as largas e ocupadas por corrimões. Segundo imaginava, alguém em direção contrária poderia lhe empurrar para o fundo do rio sobre o qual a passarela passava. Fez-se de destemido (segundo suas próprias palavras). Passou tremendo e sentindo as mesmas palpitações, mas resolveu, no entanto, não prestar atenção a elas; seria um estado normal, mais fruto de seu psicológico do que de um real problema cardíaco.

Quando findou a travessia, sentiu-se tomado de uma intensa alegria, como se houvesse reconciliado algo dentro de si que não suspeitava. Respondi que a sensação poderia ser análoga a ele ter passado no concurso, ele disse que sim. Constatou que suas dificuldades remeteram às passarelas que ele tinha que enfrentar e aos desafios que tinha ainda pela frente.

Nos encontros seguintes Lucas passou a questionar a viabilidade do projeto do pai para que ele aprovasse no concurso. Justificava esse projeto como algo que poderia lhe garantir um emprego mais seguro já em sua idade, podendo se tornar independente do pai e de suas frequentes cobranças. Indiquei-lhe outras possibilidades, investigando seus interesses na escola. Era bom aluno, obtinha as melhores notas, sobretudo em matemática, discutimos juntos outros projetos possíveis para sua vida profissional.

Pensou em estudar Mecatrônica na universidade e viu na escola técnica como uma via para o cumprimento dessa meta. A elaboração de outros possíveis foi-se dando sem muita angústia, mas já numa relação segura com o terapeuta. Várias possibilidades para seu futuro foram elaboradas e projetadas. Nesse tempo - que durou aproximadamente um mês e meio -, as crises não voltaram e ele percebeu que as alterações em seus batimentos cardíacos eram devidas às suas atividades físicas; não voltou mais ao futebol, mas lhe apetecia ainda a prática de alguns exercícios. Começou a vir às sessões de bicicleta, e relatava um certo cansaço quando chegava, além de apontar alguns traços da arquitetura da cidade que antes lhe passava despercebido, como o topo dos prédios e a elevação das construções.

As crises não voltaram, viu-se reconciliado com seus projetos e por decisão própria quis encerrar o tratamento. Sentia-se agora mais dono de si, segundo suas palavras, e gostaria de exercer uma independência maior em relação às suas próprias escolhas, o que o fazia se sentir, de alguma forma, preso às nossas sessões. Alertei-lhe sobre a necessidade em avaliarmos juntos alguns aspectos determinantes das crises que sofrera e as vantagens de um tratamento que não se finda apenas com o alívio dos sintomas.

Disse-lhe que os sintomas eram apenas uma "ponta de um iceberg" que indicava que deveríamos aprofundar mais em direção a seus problemas. No entanto, Lucas estava decidido; findas as crises e tendo-se reconciliado com o seu corpo, segundo o que disse, poderia caminhar sozinho. Nada valeu minha insistência e o paciente deu por encerrado o processo, agradecendo-me muito pela ajuda e se dizendo totalmente curado do transtorno que sofria. Após três meses do fim de nossas consultas liguei-lhe para ter notícias; disse que se curara de vez dos sintomas e que havia sido aprovado no concurso e se preparava para o curso técnico; o que fosse fazer depois decidiria mais tarde.

\section{4. $\mathrm{O}$ Caso Lucas à Vista da Fenomenologia Existencial}

Lucas revela desde o primeiro encontro, uma postura distante, tímida. Falava por gaguejos e se corrigia constantemente. Os sintomas não são, a princípio, o que o abriria ao processo psicoterápico, antes fazem um apelo àquilo que o mantém enlaçado ao mundo: a necessidade em atravessar a ponte que o ligaria a uma vida profissional digna, tal qual fora a de seu pai. Aproximar-se das palpitações, do descontrole, do medo iminente da morte é também se aproximar das experiências advindas disso, é estar com aquilo que é o núcleo de seu adoecimento. Prefere de início se relatar como de "fora" do processo, apresenta-se como quem cabe suplantar a dura missão de lidar com um estudo focado, concentrado, tal qual se apresentava no projeto do pai.

O mundo exigente do pai apareceu-lhe como pré-determinado e ameaçador à sua existência. A solicitação de que era dele a responsabilidade por seu futuro e que esse estava atrelado à aprovação no concurso, cerceava suas possibilidades de ser, o que de certa forma o sufocava, ao mesmo tempo em que, ao não se posicionar sobre isso, não conseguia empreender-se nos estudos necessários à sua aprovação.

O Terror do pânico se lhe revela quando as possibilidades de espacialização vão se reduzindo a ponto dele vislumbrar a possibilidade terrífica do abismo lhe invadir. Por um lado, temos que o núcleo do terror vivenciado por Lucas bem poderia se encontrar na morte do avô. O fato da sintomatologia do pânico ocorrer logo após o falar sobre essa morte, não garante que os ataques estejam simplesmente associados a essa. O que vale destacar na forma como Lucas compreende essa morte é que ela inaugura um abismo de continuidade, interferindo em seu modo de espacializar.

O concurso aparece sempre como um inatingível idealizado, sua posição perante a ele, confunde-se como 
uma posição diante ao pai. Posicionar-se, nesse sentido, requereria confrontar o seu projeto com o do Pai o do dele e se estabelecer em uma relação em que ele pudesse compor seu próprio futuro e seu modo de espacialização, mas isso não se deu.

Lucas se retrai frente à ameaça paterna e o desconsolo do avô morto. $\mathrm{O}$ abismo o ameaça, pois lhe aponta a possibilidade iminente de fracasso no concurso que ele mesmo passa a traçar na atitude relapsa para o seu preparo. Passar ou não passar no concurso seria a afirmação do seu próprio ser, desafio esse que ele prefere não ter que suportar. Como fuga a esse possível aniquilamento, Lucas reduz seu modo de espacialização, a ponto de reduzir seu espaço a seu quarto e às pequenas caminhadas que fazia no trajeto entre sua casa e a escola. No entanto, o mundo de fora parecia invadi-lo, a ponto de o aniquilar. A sensação de morte iminente, comum nos ataques de pânico, desvela que o nada aparece como algo que vem de encontro ao mundo do indivíduo. Algo de fora, incontrolável, ameaça sua existência como um todo.

As crises de pânico vão se tornando severas na medida em que a data do concurso vai se aproximando e Lucas vai se sentindo engalfinhado. Sua atenção, voltada às construções, mostra-nos o caráter plenamente reificado do mundo que ele estava a habitar, sem se construir, elas o chamam ao desabamento, já que como elas, ele é apenas facticidade e a queda é iminente. Nesse se desmontar Lucas não se apropria do seu modo próprio e se percebe como um "ente-intramundano" no meio dos outros.

Interessante notar que a vivência do terror da morte vai aos poucos se atenuando após a experiência com a passarela; passarela esta que ele atravessou destemidamente à procura de um estágio que lhe traria maior independência financeira em relação ao pai. Atravessar a passarela significa recuperar um modo de espacialização que fora rompido desde a morte do avô. Ao desafiá-la, novas formas de relações existenciais lhe abriram. Lucas pode vislumbrar possibilidades que antes não lhe apareciam, posto que se afundavam no abismo do terror da morte.

A possibilidade de não passar no concurso foi a primeira menção que ele fez, já como posição frente ao projeto do pai sobre ele. A possibilidade de continuar estudando no ensino médio sem a especialização técnica visando um melhor preparo para o vestibular foi outra. Existia ainda uma terceira forma de se posicionar como projeto, aprovar-se no concurso federal como meio de se realizar mais à frente um curso universitário de Mecatrônica, o que reuniria seus interesses aos do pai. Essa aproximação paulatina com seu projeto e seu modo de espacialização coincide com o fim das sintomatologias e alívio para o seu sofrimento. $\mathrm{O}$ espaço de Lucas amplia-se de tal forma que ele passa a vir às sessões de bicicleta, e sempre me trazendo detalhes novos sobre as edificações entre as ruas que ele ainda não havia notado, pois estava cego às construções e suas possibilidades.
A arquitetura já não vista como um desabamento, mas como elos que se ligam em travessias possíveis por bicicleta. Os blocos dos prédios, as pontes, os viadutos que atravessava, denotavam já a possibilidade de ser aí como projeto para alguma coisa.

\section{Considerações Finais}

Para o que nos interessa em uma análise existencial, o caso nos apresenta um exemplo de como uma categoria própria ao Dasein - a espacialidade - aparece como elemento a ser compreendido dentro do quadro de uma sintomatologia específica. Não se trata aqui de símbolo ou metáfora de algo mais profundo que se encontraria no pano de fundo da visão e significação do paciente, mas do próprio modo como ele configura um mundo específico em seu modo de espacialização.

As passarelas diziam de suas possibilidades de ser diante ao mundo, pois traziam à sua presença os desafios que lhe apareciam em sua existência. Algo que une um solo a outro, mas que paira no abismo faz relação de sentido com aquilo que Lucas vivenciava na dimensão profissional e afetiva. O Terror é esse elemento que o invadia no "entre os solos", guardando uma potência aniquiladora, pois o confrontava diretamente com a morte. Interessante notar que a morte aqui diz da possibilidade de Lucas não existir como projeto em relação a algo. A morte no humano não é simples ausência de vida, mas falta de sentido em relação a que se direcionar.

Nesse trabalho, ao falarmos sobre o terror, resgatamos uma experiência comum nos quadros de psicoses e a entendemos no contexto específico do transtorno do pânico. A diferença diagnóstica entre essas patologias devemos ter claro -, não está propriamente na experiência em si, mas na biografia do indivíduo e na história da evolução de sua patologia.

Lucas não desenvolve um processo psicótico por ter em sua biografia alguma base sobre a qual pudesse ainda se manter. Essa base é chamada por Laing (1961/1972) de "segurança ontológica" e se dá na medida em que o indivíduo sente, desde a infância, a confirmação de sua existência por parte de um outro significativo, podendo ser o pai, a mãe ou alguém com quem o indivíduo mantenha um vínculo especial e contínuo no processo de seu desenvolvimento.

Na fase em que Binswanger (1960/1987) se dedica à obra de Husserl, utilizando-se da Fenomenologia Transcendental, o autor se refere à psicose como uma descontinuidade no plano da experiência. O sujeito perderia a possibilidade de se atualizar diante do fluxo de suas experiências existenciais. Assim, há por parte do psicótico, diante de determinada experiência, a predominância de um tema único em sua existência, do qual ele não pode escapar por sua própria vontade. 
Assim, o fato de Lucas vivenciar a angústia, significá-la em seu contexto existencial, e se abrir às novas possibilidades existenciais - graças, em parte, a um encontro significativo com seu terapeuta - demonstra que em seu caso o transtorno do pânico não foi prenúncio de uma experiência da qual ele se tornaria refém, como é o surto psicótico ${ }^{6}$. A relação de parceiro existencial vivenciada no processo psicoterápico permitiu a Lucas uma abertura para o seu ser além do mundo, em termos binswangerianos, ou seja, a possibilidade de se projetar para além daquela situação imediata e desesperadora que vivenciara.

A relação do desenvolvimento do transtorno associado à morte do avô e às pressões paternas para que ele fosse aprovado no concurso, desvela como a perda de um outro significativo repercutiu de forma drástica em sua existência como um todo. Ainda assim, a figura reparadora do terapeuta como alguém a quem pudesse confiar suas angústias e temores, bem como a participação dedicada da mãe a quem confiava dava a ele algum subsídio para a realização de seus projetos. A perda de uma relação significativa como a que tinha com o avô, não significou a perda de sua própria existência, como no caso Suzanne Urban na relação com o diagnóstico do esposo, mas uma angústia intensa que lhe desvelou o nada de sua condição existencial e que possibilitou, concomitantemente, uma abertura a novas possibilidades e revisão de seu projeto.

Binswanger (1960/1987) diz ainda que, na psicose, o binômio "angústia e confiança", como modo de abertura do Da-sein, se desfaz. Assim, na neurose, angústia e confiança, embora possam estar comprometidas em algum aspecto, aparecem interconectadas na relação que o indivíduo tece com seu mundo. 0 mesmo não se dá na psicose, em que uma das dimensões sobrepõe à outra. Ora o sujeito confia sem se angustiar, como nos casos da mania, ora se angustia sem exercer nenhuma confiança, como nos delírios persecutórios presentes na esquizofrenia.

No caso Suzanne Urban, o nada se sobrepôs às suas possibilidades e sua existência se paralisou em um único tema, o mundo não lhe apareceu digno de confiança, haja vista que todos eram vistos por ela, como potências aniquiladoras de sua própria existência. Lucas foi capaz de confiar, mesmo que ainda angustiado, em uma relação significativa com seu terapeuta e nas suas próprias capacidades e possibilidades de realização.

O transtorno do pânico tem sido alvo de intensos debates entre psiquiatras, psicoterapeutas e psicanalistas, tanto do ponto de vista explicativo quanto nos modelos de tratamento. Este trabalho teve como intuito demonstrar como uma relação que se estabeleceu entre psicoterapeuta e cliente pode elucidar alguns pontos presentes na patologia e promover alívio para os sintomas em um caso específico, pelo menos por um período de seis meses.

Faltam-nos elementos para saber se os chamados "sintomas", nos dizeres do paciente, reaparecerão ul-

\footnotetext{
Cabe lembrar que os estados de pânico, tal como os vivenciados por Lucas, costumam prenunciar um surto psicótico.
}

teriormente em uma nova situação, desencadeados por novos impasses nas relações interpessoais. A idade com que eles apareceram e foram tratados, podem nos deixar otimistas quanto a isso; antes de Lucas se solidificar em um modo de fuga da angústia essa foi por ele enfrentada em uma situação específica, permitindo a abertura a possíveis dentro de sua estrutura existencial.

A adolescência já é por si só um abismo a se transpor e essa ponte, muitas das vezes, dá-se como um projeto profissional, algo com que Lucas se debateu prematuramente graças às exigências do pai. Não é comum que adolescentes de 15 anos sejam postos dessa forma diante da uma escolha de um futuro tão relevante para sua vida, o que ameaçou, sem sombra de dúvida, sua frágil estrutura existencial, ainda imatura para se posicionar diante de projetos desse tipo.

O pai não foi chamado para as sessões, justamente pelo terapeuta prever que o mesmo poderia ameaçar o tratamento. A mãe confirmava a aversão que o mesmo tinha por psicólogos e "frescuras" do tipo. As exigências dele acabariam por reforçar a sintomatologia de Lucas que, quando em ataques agudos, assustava o pai que recuava diante das exigências. Paradoxalmente, foram as próprias crises que o sensibilizaram, atenuando suas cobranças e possibilitando a Lucas um novo posicionamento.

O caso se encerra por própria iniciativa do paciente, que se sentia agora mais seguro em relação a seus próprios caminhos e que via no terapeuta um apoio fútil para esse momento. A extravagância do ato pode também nos apontar de que modo Lucas traçava para si um modo de ser sobre o abismo que depois poderia não suportar. O seu retraimento em relação a seus sentimentos e anseios, desvelado na primeira sessão, aponta-nos para a possibilidade do paciente ter-se comprometido com os projetos do pai, como meio de respondê-lo sem, no entanto, estar consciente de sua própria base existencial para a realização desses.

O cliente sai esperançoso na construção de um projeto próprio que lhe fosse viável e autônomo. E o texto aqui se cumpre ao mostrar, de uma perspectiva analítico-existencial, de que forma podemos compreender e tratar o transtorno do pânico tendo como existenciário básico a espacialidade.

\section{Referências}

American Psychiatric Association (1995). Manual Diagnóstico e Estatístico de Transtornos Mentais - DSM-IV. Porto Alegre: Artes Médicas.

Binswanger, L. (1972) Tres formas de la existencia frustrada: exaltación, excentricidad, manerismo. Buenos Aires: Amorrortu Editores (Original publicado em 1956).

Binswanger, L. (1988). Le Cas Suzanne Urban - Étude sur la schizophrénie. Saint-Pierre-de-Salerme: Gérard Monfort (Original publicado em 1957). 
Binswanger, L. (1987). Melancolie et manie. Études phénoménologiques. Paris: Presses Universitaires de France (Original publicado em 1960).

Boss, M. (1977). O modo-de-ser esquizofrênico à luz de uma fenomenologia daseinsanalítica. Revista da Associação Brasileira de Daseinsanalyse, 3, 5-28.

Chamond, J. (2011). Fenomenologia e psicopatologia do espaço vivido em Ludwig Binswanger: uma introdução. Revista da Abordagem Gestáltica, 17(1), 3-7.

Giovanetti, J. (1990). O existir humano na obra de Ludwig Binswanger. Síntese (Nova Fase), 50, p. 87-99.

Heidegger, M. (1997). Ser e Tempo I. Petrópolis: Vozes (Original publicado em 1927).

Laing, R. D. (1972). O eu e os outros. Petrópolis: Vozes (Original publicado em 1961)
Pereira, M. E. C. (1997). Pânico: contribuição à psicopatologia dos ataques de pânico. São Paulo: Lemos Editorial.

Gustavo Alvarenga Oliveira Santos - Psicólogo, Mestre em Psicologia Clínica pela Pontifícia Universidade Católica de Campinas e Docente na Universidade Federal do Triângulo Mineiro (UFTM). Endereço Institucional: Rua Getúlio Guaritá, 159 (Bairro Nossa Senhora da Abadia). CEP 38025-440. Uberaba/MG. Email: gustavo.alvarenga@ psicologia.uftm.edu.br

Recebido em 06.07.2012

Primeira Decisão Editorial em 15.10.2012

Aceito em 14.12 .12 